\title{
Big-Fish Lies: a Simple Application to Monetary Economics*
}

\section{Mentiras de Pescador: um Aplicação Simples à Economia Monetária}

\author{
Marcelo de C. Griebeler ${ }^{a}$
}

\begin{abstract}
We provide an alternative to Bayesian updating in cheap-talk games, which does not require the receiver know the sender's type distribution. This is done through an anecdotal application, in which a fisherman reports to his friends the size of a fish he caught in the city's lake. Our findings show that the fisherman will always report a size higher than the mean, and this reported value is independent on the actual size of the caught fish. This result holds as long as the fisherman presents no aversion to lie and no reputation concerns. We illustrate the applicability of our approach through a simple model of monetary economics, in which a central bank must choose the level of the economy's interest rate in order to control inflation based on the inflation expectation reported by heterogeneous and self-interested agents.
\end{abstract}

Keywords: cheap-talk; Bayesian updating; monetary economics.

Resumo: Este artigo oferece uma alternativa à atualização bayesiana em jogos de cheap talk, a qual não exige que o receptor saiba a distribuição do tipo do remetente. Isso é feito por meio de uma aplicação anedótica, em que um pescador relata aos amigos o tamanho de um peixe que pescou no lago da cidade. Nossos resultados mostram que o pescador sempre relatará um tamanho maior do que a média e que esse valor relatado é independente do tamanho real dos peixes capturados. Esse resultado é válido enquanto o pescador não apresentar aversão à mentira e nenhuma preocupação com sua reputação. Ilustra-se a aplicabilidade dessa abordagem por meio de um modelo simples de economia monetária, em que um banco central deve escolher o nível da taxa de juros da economia a fim de controlar a inflação com base na expectativa de inflação relatada por agentes heterogêneos e com interesses próprios.

Palavras-chave: cheap-talk; atualização bayesiana; economia monetária.

JEL Classification: D83; D01; C79.

\footnotetext{
* We thank the participants of seminars at FEA - RP, UEPG and PPGE/UFRGS for their constructive comments. All the remaining errors are ours. This research was supported in part by The Brazilian National Council for Scientific and Technological Development (CNPq) under grant number 305838/2017-2.

Universidade Federal do Rio Grande do Sul (UFRGS), Programa de Pós-Graduação em Economia (PPGE). Porto Alegre, Rio Grande do Sul, Brasil.
} 


\section{Introduction}

Since the seminal paper by Crawford and Sobel (1982) cheap-talk games have been modeled within the standard framework of signaling games. The sequence of movements in the communication between a sender and a receiver is, in general, as follows: the sender learns some realization of a random variable , then selects a message to send to the receiver; the receiver, who does not observe the realization of , receives the message from the sender and then chooses an action. The basic assumptions in this context are that the probability distribution of is common knowledge and the receiver knows the sender's type distribution, such that the former is able to update his prior about the latter after receiving, which is made by using the Bayes rule (GREEN; STOKEY, 2007; SOBEL, 2013).

As we can see, using Bayesian updating requires that the receiver have some knowledge about the sender. However, in several circumstances may be difficult to envision that the receiver knows the sender type's distribution and thus has information enough to construct his priors. While it is plausible to assume that a decision maker does have such knowledge when he consults a known expert periodically, this may not be the case when it is the first consultation with an unknown one. As another example, consider a situation with many different experts ${ }^{1}$ and a single decision maker who is seeking advice from them. As the number of experts increases, the difficulty to know the distribution of the each one's type increases as well. In such cases it seems reasonable to think about an alternative that does not require the knowledge about the type's distribution.

In this paper we provide a model of cheap-talk which does not require the receiver know the sender's type distribution. Although we still assume that the distribution of the variable of interest (in the above setting) is common knowledge, we allow the receiver to have no information about sender's preferences or behavior. This is made by introducing a function that measures the probability of the sender lying, given that the receiver has observed the sent message. The idea is that by knowing the probability distribution of the variable of interest, the receiver gives lower weight to reported values that are distant from the mean. Thus, the expected value of the variable can be computed, and the receiver can choose his action based on such a value.

We present our model through an anecdotal application, in which a fisherman reports to his friends the size of a fish he caught in the city's lake. He wants his friends to believe he caught the largest possible fish, such that he faces the tradeoff every liar does: he has an incentive to overstate the fish size, but by doing so the reported size distances from the mean of fish size in that lake, which is known

1 On models with many senders see Ambrus and Takahashi (2008), Battaglini (2002), Gilligan and Krehbiel (1989). 
by his friends. The trade-off between the magnitude of the reported value and its trustworthiness holds as long as the group of friends does not know anything about the fisherman's preferences and behavior but knows the distribution of fishes in the city's lake.

Our findings show that the fisherman will always report a size higher than the mean, and this reported value is independent on the actual size of the caught fish. Hence, he will always lie - unless the actual size of the caught fish be equal to his optimal value - but the reported value will not necessarily be higher than the true one. In fact, if he caught a fish whose size is higher than the optimal value obtained in his optimization problem, he will understate the true size. However, the independence between the reported and the actual value may be not appealing in several applications. We overcome such a difficulty by adding a moral cost of lying, which decreases the magnitude of the lie. Reputation is also studied when we add dynamics in the baseline model, such that the trustworthiness of the reported value in the second period depend on the "forecast error" (i.e. the magnitude of the lie) in the first one. This modification also makes the reported value be closer to the true one.

A straightforward application in monetary economics is also presented ${ }^{2}$. We study the central bank's choice of the level of the economy's interest rate when its objective is to control inflation. Among a set of simplifying assumptions, we suppose that only interest rate and economy's inflation expectation affect inflation. As inflation expectation is not observed by the central bank, it is reported by a forecaster (e.g a commercial bank) instead, we have a communication game. We believe that this application fits our basic model well because the number of forecasters who report the inflation expectation to the monetary authority is large and they may have very different incentives to lie. For instance, while a commercial bank may have assets indexed to the interest rate, and thus wants the highest possible interest rate, another financial institution may have debts indexed to the same variable, which makes it want to report a lower expectation in order to induce a decrease in the rate. Those two features make it difficult for the central bank to know any information about the forecasters - even the distribution of their types.

An important remark is that our results hold whenever the receiver knows nothing about the sender's utility, that is whenever the only common knowledge information is the distribution of the variable of interest. Thus, our model does not apply to situations in which the receiver knows that the sender has incentives to overstate (or understate) his reported value. For example, suppose that an employer is interviewing a candidate for a vacant job in his company. Suppose also that the employee's wage will be determined based on the candidate's productiv-

2 An important example of the literature on the applications of Communication Games on Monetary Economics is Stein (1989). 
ity. Thus, the employer is sure that there is no incentive for a particular candidate to report a variable related with productivity lower than the mean of the pool of candidates. In this case, our approach is not suitable, and the standard models of cheap-talk will surely perform better.

While there is a clear advantage in adopting the model we suggest in this paper, namely there is no need that the receiver knows the sender's type distribution, there is also some drawbacks when it is compared to Bayesian updating. For instance, our approach requires ad hoc functional form for the function which measures the probability that the sender is telling the truth - and for the moral and reputation costs as well, whenever we extend the model in those directions. As we comment in section 4, the choice of those functional forms is critical, such that different functions may generate different results. In fact, our results are particularly dependent on the assumption that the variable of interest is normally distributed. Nevertheless, as the aforementioned application to the monetary economics shows, there are circumstances which Bayesian updating is not satisfactory, and our alternative model may fill this gap.

The main contribution of this paper is to provide an alternative method of modelling cheap-talk games, without requiring that the receiver know the probability distribution of the sender's type. Thus, our results contribute to the literature of sender-receiver games in general (CRAWFORD; SOBEL, 1982; GREEN; STOKEY, 2007; SOBEL, 2013), which use Bayesian updating. In particular, as the application to monetary economics developed in section 3 shows, our approach is notably suitable for modeling games with many senders and one receiver, such as those analyzed by Battaglini (2002), Ambrus and Takahashi (2008) and Gilligan and Krehbiel (1989). Another paper which investigates the role of the number of experts (senders) in the information's quality is Krishna and Morgan (2001), which found that, when there are two experts, it is always beneficial for the receiver to consult both if they are biased in opposite directions.

Because our model is extended to incorporate a moral cost of lying, it is also related with the literature which analyzes lying aversion. Some remarkable empirical papers in this field which are close to ours are Gneezy (2005), Chakravarty et al. (2011) and López-Perez and Spiegelman (2013). While Gneezy (2005) performs a seminal study on general aspects of lying aversion by using a standard sender-receiver game, Chakravarty et al. (2011) analyzes the interaction between friendship and deceptive behavior, and López-Perez and Spiegelman (2013) tries to isolate the effect of pure lying aversion, among the several incentives to tell the truth people face. Further, Erat and Gneezy (2012) investigates the aforementioned issues by focusing only on the so-called white lies. Accordingly, our model can be seen as a theoretical contribution to this incipient literature. 
The dynamic extension we provide, the one that incorporates reputation concerns, is related to another important stream of the literature of communication games, namely the one which considers the possibility of biased reported information as a consequence of such a concern. Leading contributions to this field are those of Morris (2001) and Kartik (2009). While in the former the reputation concern may make the true information be misreported because of the receiver's initial belief that the sender himself may be "biased" - e.g. racist, when the sender is an expert and the receiver is a policymaker, and the subject is an affirmative action -, in the latter the lying costs are the responsible of the biased result. Both papers present some similarities to our results, given the endogenous nature of the bias.

Given that we provide an alternative to Bayesian updating, our model has similarities with works which adopt non-Bayesian updating, such as Epstein (2006), Epstein et al. (2008) and Epstein et al. (2010). On the one hand, those studies are quite more general than ours, such that they can be applied to different problems. In particular, their approach is suitable even for models with many senders. On the other hand, it requires that the receiver know the distribution of the types, like in the standard models with Bayesian updating, such that the major difference related to the latter is the way the updating is performed, and not the informational requirements. Our model, in contrast, requires less information, but is more limited in terms of applications.

Finally, our application to monetary economics relates to the literature on communication between central banks and society (banks and other financial institutions, especially). In particular, our model is close to the study of Griebeler (2019), which, to best of our knowledge, is the only paper to investigate the consequences for the communication between a central bank and a survey respondent (a forecaster) - someone who reports the inflation expectation to the monetary authority -- when the latter is biased, that is, when there are incentives to report it strategically. The difference, however, is that Griebeler (2019), uses a standard cheap-talk game, whereas we propose an alternative approach. Our model also presents some similarity with Stein (1989), other paper to follow the stander-cheap talk literature. Nevertheless, the communication analyzed by this latter study focus on the signals central bank can send to society, which makes it rather different from our setting.

The paper is organized as follows. The next section presents a model of bigfish lies, where we use an anecdote to present our alternative to Bayesian updating in cheap-talk models. We start with a baseline model, which represents the typical trade-off face by any liar, and then we add aversion to lie and reputation concerns in the sender's utility. Section 3 suggests an application of our model to a problem in monetary economics, and thus illustrates the strength of our approach for some 
specific situations. Section 4 concludes by analyzing how dependent on the assumptions made throughout the text our results are. All the proposition's proofs are presented in the appendix A.

\section{A Model of Big-Fish Lies}

In this section, we build the model of big-fish lies and thus obtain our main results.

\subsection{Baseline Model}

A fisherman must tell the size of the fish that he caught in the city's lake to his friends. Although they do not observe the size of this specific fish, they do know the distribution of size of the fishes that live in the city's lake. Let us assume that the fish size $x$ is normally distributed with mean $\mu>0$ and variance $\sigma^{2}$. Moreover, let $\tilde{\mathrm{X}}$ be the realization of the random variable $x$ - the actual fish size, observed only by the fisherman. The fisherman wants their friends to believe that he caught a big fish, but if he overstates the size reported to them, they will distrust his announcement ${ }^{3}$. Therefore, the trade-off faced by him is the same that every liar does.

As the support of the normal distribution is $R$ but the fish size is $\geq 0$, we must impose an assumption that ensures that the probability of any negative size is inconsiderable. By doing so we can use all the desirable properties that the normal distribution offers us and thus do not need to search for a probability distribution supported on the semi-infinite interval $[0, \infty)$.

Assumption 2.1: $\mu$ and $\sigma^{2}$ are such that $F(0)<\epsilon$, where $\epsilon>0$ is an arbitrary small constant and $\mathrm{F}(\cdot)$ is the probability distribution function of the normal distribution.

Given that the probability distribution is common knowledge, his friends can evaluate the probability of the fisherman telling the truth when is reported, as the next assumption states.

Assumption 2.2: His friends assign the probability of the fisherman telling the truth when $x$ is reported according to ${ }^{4}$

3 We consider the most common case, but the fisherman might have incentive to tell that he caught a small fish as well. For example, suppose that he has promised to share the fish with his friends. In this case, the smaller the fish they believe to have been caught, the larger the share that the fisherman appropriates.

By choosing a suitable it is possible to show that is a probability density function, that is, $\int_{0}^{+\infty} P(x) d x=1$. The function established in the assumption 2 is not the only possible choice for $\mathrm{P}(x)$, such that there are even simpler options. However, we believe that this functional form is consistent with the intuition of our model. 


$$
P(x)=1-\left(2 \int_{\mu}^{x} f(y) d y\right)^{2},
$$

where $\mathrm{f}(\cdot)$ is the probability density of the normal distribution.

Observe that we implicitly assume that fisherman's friends do not know his utility function, such that they assign positive probability for sizes lower than the mean. This means that they do not know the incentives to overstate the fish size that the fisherman faces. They may believe, for instance, that he would report a smaller fish to avoid sharing it with his friends - see footnote 4 . In fact, they do not even have a prior about his preferences, which in turn rules out the possibility of Bayesian updating after receiving the reported fish size.

We can sustain the above assumption by arguing that the fisherman may have to tell the fish size to a group of strangers, such that those people do not know anything about his preferences. Another possibility is that the same group of people may face many different fishermen, which may make it difficult to characterize each one of them separately. In addition, in several applications, such as the one of section 3, in which inflation expectation are reported by a large group of economic forecasters, the assumption does hold, once it is very difficult for the central bank to know something about their preferences.

The functional form of (1) has some desirable properties: (i) $\mathrm{P}(\mu)=1$; (ii) $\mathrm{P}$ (x) is symmetrical, such that $P(x)=P(-x)$; and (iii) $\lim _{x \rightarrow+\infty} P(x)=\lim _{x \rightarrow-\infty} P(x)=0$. Given their limited information, their friends assign the maximum probability when the reported value is equal to the mean. In addition, equal-size positive and negative deviations from the mean decrease the probability at the same magnitude. Finally, as the deviation becomes higher - with either very high or very low $x-$, the assigned probability approaches zero. Some further properties of the probability function are established below.

Proposition 2.4: The probability (1) is a bell-shaped, quasiconcave function of $x$ and achieves its unique global maximum when $\mathrm{x}=\mu$.

The fisherman's utility is given by , that is, it depends only on the "expected value" of the fish size (in his friends' point of view) ${ }^{5}$. This means that it is desirable to increase the reported value, but by doing so he may also distance the reported value from the mean, which decreases the probability. This is the trade-off faced by the fisherman: he would want to exaggerate the reported value, but this would reveal that he is lying.

Given our assumptions, it is straightforward to show that has some desirable properties.

5 In fact, to be a true expected value, we have to assume that, given their limited information, his friends believe that when he is lying - which happens with probability $1-\mathrm{P}(\mathrm{x})$, the true fish size is zero, that is, he did not catch any fish. 
Proposition 2.5: The utility function is a quasiconcave function of for all .

The above proposition guarantees that the first order condition (FOC) of the fisherman's problem is both necessary and sufficient for the maximum. Its FOC is given by following expression, that is,

$$
\left[1-\left(2 \int_{\mu}^{x} f(y) d y\right)^{2}\right]-8 x f(x) \int_{\mu}^{x} f(y) d y=0 .
$$

Because (2) is an integral equation involving the normal distribution, it is not clear that it has a solution. We must analyze this subject.

Proposition 2.5: For given $\sigma^{2}$, there exists $\bar{\mu}>0$ such that the fisherman's FOC (2) has a unique solution. Let $x^{*}$ be such a solution, then $x^{*}$ is a maximum of $\mathrm{U}$ (x) and $\bar{\mu}<\mathrm{x}^{*}<\bar{\mu}+\sigma$. Moreover, $\mathrm{x}^{*}$ is independent on $\tilde{\mathrm{x}}$.

The above existence result is straightforward: although we cannot guarantee the existence of solution for (2) for all $(\mu, \sigma 2)$, there exists a given mean $\bar{\mu}$ that guarantees both the existence and the uniqueness of this solution. The figure below presents the fisherman's utility function and the probability $\mathrm{P}(\cdot)$ for $\mathrm{x} \sim \mathcal{N}(2,2)$. One can see that both are bell-shaped and that $\bar{\mu}<x^{*}<\bar{\mu}+\sigma$, as the propositions 2.4 and 2.5 state.

Figure 1 - Fisherman's utility and the probability function

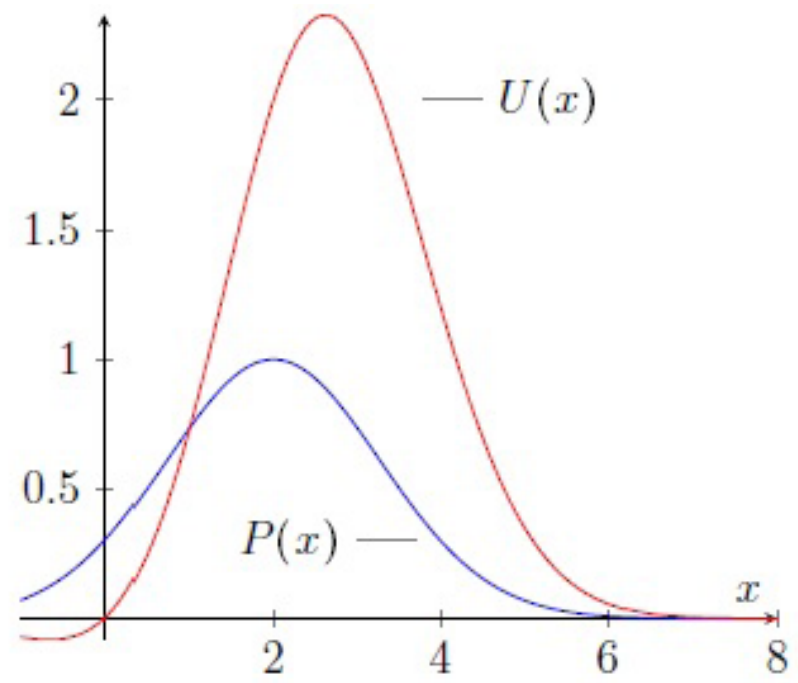

Source: created by the author. 
Notice that the realization of the random variable $\tilde{x}$, the actual fish size, observed only by the fisherman, play no role in his optimal choice. Thus, this result is similar to those of a babbling equilibrium, in which messages are completely uninformative, so that no information about the state is credibly transmitted to the receiver. In fact, it does not affect his utility, since there is neither an ex-post penalty on his utility imposed by the principal in case of reporting a lie nor a moral cost of lying that he must pay, for example. We consider these and other ways of incorporating the effect of $\tilde{x}$ on the optimal choice later.

The second part of proposition 2.5 is rather important because it claims that the fisherman will always report a value higher than the mean. As $\tilde{x}$ does not affect his choice, that means that he will always lie unless $\tilde{x}=x^{*}$. However, there is an upper bound of the reported value, namely $\mu+\sigma$ for any $(\mu, \sigma) \in \mathrm{R}_{++}^{2}$. Thus, given, the fisherman's lie is never higher than such a threshold, which is also independent on the actual fish size. The existence of this upper bound is other effect of the typical liar's tradeoff. We discuss how much this result depends on the assumptions made about the probability distribution and the functional form of $\mathrm{P}(\mathrm{x})$ later in section 4 .

Given that the actual fish size does not affect the fisherman's optimal decision, one can wonder why their friends should take into account the reported size. In fact, his report is not informative at all, such that after observing it, the group of friends learns nothing about $\tilde{x}$. However, recall that our major assumption is that they indeed do not know anything about the fisherman's preferences, which implies that they are not able to figure out that his choice is independent on the actual fish size. Thus, they may consider the fisherman as an "expert" and ponder his "advice".

The role of the uncertainty on the optimal choice is analyzed below.

Proposition 2.6: The optimal choice $\tilde{\mathrm{x}}$ is a strictly increasing function of $\sigma^{2}$.

Given $x$, a higher level of uncertainty, measured by the variance of the distribution of $x$, makes the receiver assign a higher probability of the agent being telling the true. Geometrically, a higher variance makes not only the normal distribution's tails heavier, but it also increases the sender's utility for any given $\mathrm{x}$. The reason is that the utility function $U(\mathrm{x})$ is displaced northeast, which makes the optimal choice $X^{*}$ be higher. In fact, a higher level of uncertainty benefits the fisherman because now their friends know that the chance of catching large fish in the city's lake is not too small, such that he has a margin to lie larger than he did when there was low level of uncertainty. Given that the mean is fixed, the higher the uncertainty the more incentive to lie - the more the distance between the reported value and the mean.

So far we have not used the cheap-talk standard notation. However, it is straightforward to present our model in such a basic setting. Let the receiver's utility be given by $\mathrm{V}(\mathrm{a}, \mathrm{x})=(\mathrm{a}-\mathrm{E}(\mathrm{x}))^{2}$, where $a$ is his action. Observe that we are assum- 
ing that all the fisherman's friends are represented by a single agent (the receiver). Moreover, let $\mathrm{U}(\mathrm{a}, \mathrm{x})=\mathrm{xP}(\mathrm{x})$ be the utility of the sender (fisherman). Now, assume that the receiver knows nothing about the sender - not even the distribution of his type - but does know the distribution of $x$ and uses $\mathrm{E}(\mathrm{x})=\mathrm{P}(\mathrm{x}) \mathrm{x}$ to calculate the expected value of the reported variable, and the sender knows the receiver's utility. Thus, the sender is able to anticipate the receiver's best response $a(x)=x P(x)$ and then will optimize $\mathrm{U}(\mathrm{a}, \mathrm{x})=\mathrm{xP}(\mathrm{x})$, which is the same problem we discussed above.

\subsection{Aversion to Lie}

In a static setting, one way of making the fisherman's optimal choice depend on the actual size of the caught fish is by adding a cost of lying. This can happen whenever the fisherman dislikes lying - he may have a certain degree of aversion to it -, such that this loss of utility may be seen as a moral cost. In fact, as empirical literature has reported (CHAKRAVARTY et al., 2011; GNEEZY, 2005), even if lying is rewarded, people often set their own boundaries between unethical and self, or socially, approved deception, weigh the costs and benefits of lying. This may make them choose to tell the truth even when it is economically disadvantageous to do so.

A suitable manner to model lying aversion is by assuming that the fisherman's utility function now is $\mathrm{V}(\mathrm{x}, \tilde{\mathrm{x}})=\mathrm{U}(\mathrm{x})-\lambda(\mathrm{x}, \tilde{\mathrm{x}})$, where $\lambda(\cdot)$ is an increasing function of $|x-\tilde{x}|$. For example, $\lambda(x, \tilde{x})=\alpha(x-\tilde{x})^{2}$ with $\alpha>0$ may measure the moral cost associated with his lies. Observe that $\lambda$ measures the degree of lie aversion: the higher $\lambda$ the higher the disutility from lying.

Proposition 2.7: Suppose that the fisherman's utility function is $\mathrm{V}(\mathrm{x}, \tilde{\mathrm{x}})=\mathrm{U}(\mathrm{x})-\lambda(\mathrm{x}, \tilde{\mathrm{x}})$, where $\lambda(\mathrm{x}, \tilde{\mathrm{x}})=\alpha(\mathrm{x}-\tilde{\mathrm{x}})^{2}$, with $\alpha>0$, measures the moral cost of lying. Then:

a) for given $\sigma^{2}$ and $\tilde{\mathrm{x}}$, there exists $\overline{\bar{\mu}}>0$ and $\underline{\alpha}, \bar{\alpha} \in \mathrm{R}$, such that if $\alpha \in \mathrm{R} \backslash(\underline{\alpha}, \bar{\alpha})$, the fisherman's problem has a maximum $\mathrm{x}^{*}(\tilde{\mathrm{x}})$;

b) $\left|x^{*}(\tilde{x})-\tilde{x}\right|<\left|x^{*}-\tilde{x}\right|$, that is, the optimal reported size is closer to the actual one than it is in the case without moral cost;

c) when $\tilde{\mathrm{x}}<$, if $\alpha>1 /[2(\overline{\bar{\mu}}\}-\tilde{\mathrm{x}})>\bar{\alpha}$, then $\mathrm{x}^{*}(\tilde{\mathrm{x}})<\mu$.

Notice that $\mathrm{V}(\cdot)$ is a sum of a quasiconcave function, $\mathrm{U}(\cdot)$, and a concave function, $-\lambda(\cdot, \tilde{\mathbf{x}})$, which does not allow us to guarantee quasiconcavity of $V$. This drawback makes statements about existence and uniqueness of the solution different from those of proposition 2.5. First, now we need a further condition to guarantee the concavity of $V$ at the optimal, namely either $\alpha<\underline{\alpha}$ or $\alpha>\bar{\alpha}$. The idea is that with a low (high) $\alpha$, the first (second) term of the sum in $V$ has a relatively higher (lower) weight in $V$, and given that it is quasiconcave (concave), the maxi- 
mum is guaranteed. Put differently, either a sufficiently low or a sufficiently high moral cost of lying is a sufficient condition to $\mathrm{x}^{*}(\tilde{\mathrm{x}})$ be a maximum of $V$.

The introduction of moral costs makes the fisherman decrease the magnitude of the lie, as item 2 and 3 of the above proposition states. For instance, when the actual size of the caught fish is lower than the mean, for a sufficiently high level of aversion to lie the fisherman chooses to report a size lower than the mean. Recall that in the baseline model, the value reported is always higher than the mean, such that now we can notice the strength of the moral cost in driving the fisherman's choice. The threshold that defines whether $\alpha$ is sufficiently high depends on the distance between the mean and actual size: the higher such a distance - for a given mean, the smaller the caught fish - the lower is the threshold, such that the moral cost does not need to be too high in order to make the fisherman choose $\mathrm{x}^{*}(\tilde{\mathrm{x}})<$. In fact, proposition 2.7 formalizes the common sense that a person who does not like lying will not be a good liar.

The function chosen to embody the moral costs in the fisherman's utility was made in ad hoc manner. In fact, there are other functional forms that satisfy the requirement of being increasing in the deviation from the true value $\tilde{x}$, such as $\bar{\lambda}(\mathrm{x}, \tilde{\mathrm{x}})=-\alpha|\mathrm{x}-\tilde{\mathrm{x}}|$ and $\hat{\lambda}(\mathrm{x}, \tilde{\mathrm{x}})=-\alpha(\mathrm{x}-\tilde{\mathrm{x}})^{4}$ with $\alpha>0$. We choose the particular form $\lambda$ above because of its simplicity, and due to the fact of being widely used in cheap-talk models. However, the main result of this section, namely that a moral cost drives the reported size toward the actual one, thus decreasing the magnitude of the lie, holds for any functional form that satisfies the required properties.

\subsection{Dynamics and Reputation}

Suppose now that the fisherman caught two fishes in different moments, such that he must tell the size of each fish to his friends in different periods. Let the actual fishes' sizes be given by $\widetilde{x_{1}}$ and $\widetilde{x_{2}}$, where the subscript indexes the periods $t=1,2$. It is reasonable to assume that their friends observe $\widetilde{x_{1}}$ in the beginning of the second period, such that they penalize the fisherman whenever he lies $-\mathrm{x}_{1}^{* *} \neq \widetilde{\mathrm{x}_{1}}$, where $x_{1}^{* *}$ is the reported size in the first period in the model with two periods. We also assume that the $\mathrm{x}_{\mathrm{t}} \sim \mathcal{N}\left(0, \sigma^{2}\right)$ for $t=1,2$ and $\mathrm{x}_{1}$ and $x_{2}$ are independent ${ }^{6}$. All this information is common knowledge.

We can model the punishment by assuming that there are reputational costs in lying, namely the trustworthiness of the report of second period $x_{2}^{* *}$ is lower whenever the fisherman lies in the first period ${ }^{7}$. A suitable way to model such pun-

$6 \quad$ Observe that this requirement can hold jointly with Assumption 2.1, so that the previous framework still applies.

7 A good survey on reputation effects both under Bayesian and non-Bayesian updating may be found in Cabral (2005). 
ishment is through the following function, which measures the probability of the fisherman telling the truth when is reported, given that $\widetilde{x_{1}}$ was observed and $x_{1}$ was the value reported in the first period:

$$
\pi\left(\mathrm{x}_{2} \mid \mathrm{x}_{1}, \widetilde{\mathrm{x}_{1}}\right)=\delta\left(\mathrm{x}_{1}, \widetilde{\mathrm{x}_{1}}\right) \mathrm{P}\left(\mathrm{x}_{2}\right),
$$

where $\mathrm{P}(\cdot)$ is the probability that measures the trustworthiness in the static model, given by (2.1), and $\delta: R \rightarrow[0,1]$ is the reputation function, which we define as

$$
\delta\left(\mathrm{x}_{1}, \widetilde{\mathrm{x}_{1}}\right)=\mathrm{e}^{-\left(\mathrm{x}_{1}-\widetilde{\mathrm{x}_{1}}\right)^{2}} .
$$

In a similar way to the probability function (1), the reputation function has some desirable properties. First, when the fisherman did not lie in the first period, that is, , there is no loss of reputation, such that $\delta\left(\widetilde{x_{1}}, \widetilde{x_{1}}\right)=1$ and thus $\pi\left(\mathrm{x}_{2} \mid \mathrm{x}_{1}, \widetilde{\mathrm{x}_{1}}\right)=\mathrm{P}\left(\mathrm{x}_{2}\right)$. Second, $\delta\left(\mathrm{x}_{1}, \widetilde{\mathrm{x}_{1}}\right)$ is symmetric around its maximum, which is achieved at $x_{1}=\widetilde{x_{1}}$, as we have seen. Thus, we have $\delta\left(x_{1}, \widetilde{x_{1}}\right)=\delta\left(-x_{1}, \widetilde{x_{1}}\right)$, which means that only lie's magnitude is important and not whether it overstated or understated the true value. Finally, the reputation function is bell-shaped, such that $\lim _{\mathrm{x}_{1} \rightarrow+\infty} \delta\left(\mathrm{x}_{1}, \widetilde{\mathrm{x}_{1}}\right)=\lim _{\mathrm{x}_{1} \rightarrow-\infty} \delta\left(\mathrm{x}_{1}, \widetilde{\mathrm{x}_{1}}\right)=0$ for any given $\widetilde{\mathrm{x}_{1}}$. This means that as the lie increases the trustworthiness of the fisherman's report approaches zero ${ }^{8}$.

In the two-period model, the fisherman's utility has the following form $\mathrm{W}\left(\mathrm{x}_{1}, \mathrm{x}_{2}\right)=\mathrm{U}\left(\mathrm{x}_{1}\right)+\beta \mathrm{U}\left(\mathrm{x}_{2}\right)$, where $\beta \in(0,1)$ is his intertemporal discount rate and we have assumed additivity for the sake of simplicity. By substituting the instantaneous utility function in the previous expression, we are able to set the fisherman's optimization problem, namely

$$
\max _{\mathrm{x}_{1}, \mathrm{x}_{2} \in \mathrm{R}} \mathrm{x}_{1} \mathrm{P}\left(\mathrm{x}_{1}\right)+\beta \mathrm{x}_{2} \delta\left(\mathrm{x}_{1}, \widetilde{\mathrm{x}_{1}}\right) \mathrm{P}\left(\mathrm{x}_{2}\right)
$$

The solution can be found through the problem's FOC:

$$
\begin{gathered}
\mathrm{x}_{1} \mathrm{P}^{\prime}\left(\mathrm{x}_{1}\right)+\mathrm{P}\left(\mathrm{x}_{1}\right)-2\left(\mathrm{x}_{1}-\widetilde{\mathrm{x}_{1}}\right) \mathrm{e}^{-\left(\mathrm{x}_{1}-\widetilde{\mathrm{x}_{1}}\right)^{2}} \beta \mathrm{x}_{2} \mathrm{P}\left(\mathrm{x}_{2}\right)=0 \\
\beta \mathrm{e}^{-\left(\mathrm{x}_{1}-\widetilde{\mathrm{x}_{1}}\right)^{2}}\left[\mathrm{x}_{2} \mathrm{P}^{\prime}\left(\mathrm{x}_{2}\right)+\mathrm{P}\left(\mathrm{x}_{2}\right)\right]=0,
\end{gathered}
$$

$8 \quad$ There are several other functional forms which are suitable to model the reputation effects on the fisherman's utility. For instance, one can consider that the penalty is larger when the reported value is higher than the true one than when it is lower. In this case, the reputation function would be asymmetric. 
where we choose to show $\delta^{\prime}\left(\mathrm{x}_{1}, \widetilde{\mathrm{x}_{1}}\right)$ explicitly in order to make the results below more easily understandable.

Observe that there is no change in the second period's optimal choice, since the expression between brackets in (7) is identical to (2), and thus $x_{2}^{* *}=x_{1}^{*}$. In fact, because $t=2$ is the last period, there is no loss in terms of reputation in lying and the fisherman's trade-off is the same as the static model, namely between the highness of his report and its trustworthiness. In the first period, however, he must now take into account the effects of his potential lie on his reputation - and thus on the trustworthiness of $x_{2}$. This creates a different trade-off: he wants his friends to believe that the fish is big, but by overstating the actual fish size his report becomes less trustworthy and he loses reputation, which affects his utility in the next period.

We have seen that (7) has a solution $x_{2}^{* *}=x_{1}^{*}>\mu$. Now we must show that (6) has solution as well.

Proposition 2.8: Suppose that the fisherman's utility function is $\mathrm{W}\left(\mathrm{x}_{1}, \mathrm{x}_{2}\right)=\mathrm{U}\left(\mathrm{x}_{1}\right)+\beta \mathrm{x}_{2} \delta\left(\mathrm{x}_{1}, \widetilde{\mathrm{x}_{1}}\right) \mathrm{P}\left(\mathrm{x}_{2}\right)$, where $\delta\left(\mathrm{x}_{1}, \widetilde{\mathrm{x}_{1}}\right)$ is the reputation function, given by $\delta\left(\mathrm{x}_{1}, \widetilde{\mathrm{x}_{1}}\right)=\mathrm{e}^{-\left(\mathrm{x}_{1}-\widetilde{\mathrm{x}_{1}}\right)^{2}}$. Then:

a) for given $\sigma^{2}$ and $\widetilde{x_{1}}$, there exists $\bar{\mu}>0$ and $\bar{\beta} \in(0,1)$ such that if $\beta<\bar{\beta}$, then the fisherman's dynamic problem has a maximum $\left(\mathrm{x}_{1}^{* *}, \mathrm{x}_{2}^{* *}\right)$;

b) $x_{2}$ is independent on $\widetilde{x_{2}}$ and $x_{2}^{* *}=x_{1}^{*}>\bar{\mu}$ for any set of parameters, where $x_{1}^{*}$ is the solution of the baseline model;

c) $\left|x_{2}^{* *}-\widetilde{x_{1}}\right|>\left|x_{1}^{* *}-\widetilde{x_{1}}\right|$ for any set of parameters, that is, the optimal reported size in the first period is closer to the actual one than it is in the

d) when $\widetilde{\mathrm{x}_{1}}<\mu$, if $\bar{\beta}>\beta>\frac{\mathrm{e}^{\left(\mathrm{x}_{1}-\widetilde{\mathrm{x}_{1}}\right)^{2}}}{\mathrm{x}_{2} \delta\left(\mathrm{x}_{1}, \widetilde{\mathrm{x}_{1}}\right) \mathrm{P}\left(\mathrm{x}_{2}\right)}$, then $\widetilde{\mathrm{x}^{* *}}<\mu$.

The existence part of proposition 2.8 is somehow weaker than the one of proposition 2.5. As once can see in the item 1 above, we now have an additional requirement to ensure the concavity of the utility function at the optimum, namely $\beta<\bar{\beta}$ This means that if the fisherman is impatient enough - or puts sufficiently low weight on future $-\left(\mathrm{x}_{1}^{* *}, \mathrm{x}_{2}^{* *}\right)$ gives him the maximum utility. Once we are not able to show that $W$ is quasiconcave, a lower $\beta$ makes the second term of $W$, $\beta \delta\left(\mathrm{x}_{1}, \widetilde{\mathrm{x}_{1}}\right) \mathrm{x}_{2} \mathrm{P}\left(\mathrm{x}_{2}\right)$, insignificant relative to the first one, $\mathrm{x}_{1} \mathrm{P}\left(\mathrm{x}_{1}\right)$, which we have already known that is quasiconcave (proposition 2.4). Furthermore, the impossibility of showing the quasiconcavity of $\mathrm{W}$ implies that there is no longer guarantee that the solution is unique.

As in the static model with moral costs, the fisherman reports a fish size closer to the true one in the first period than it does in the baseline model when he has reputation concerns. This is stated in the item 3 of proposition 2.8. With regard to item 2, observe that, although now the actual size of the caught fish affects the fisherman's optimal choice in the first period, the reported size in the second one 
is independent on both $\widetilde{x_{1}}$ and $\widetilde{x_{2}}$. The intuition is simple: since that the second period is the last one, the fisherman's choice is identical to one of the static model, which we have already seen that is independent on the true fish size.

The strength of the incentive created by the reputation function is showed by the item 4 of proposition 2.8 When the actual size of the fish caught in the first period is lower than the mean of those in the city's lake, the fisherman reports a value lower than the mean as well, as long as he is sufficiently patient. Given that the gains from reputation are felt in the second period, the incentive to tell the truth actually, to decrease the magnitude of the lie - is stronger when the fisherman puts sufficiently high weight on future. Recall that in the absence of any incentive to tell the truth, in the baseline model, the size reported by the fisherman is always larger than the mean, which highlights the importance of the result.

\section{An Application to Monetary Theory}

Consider the following application of our model. A central bank wants to control inflation $\pi\left(i, \pi^{\mathrm{e}}\right)$ - e.g., inflation target may be $\pi^{*}=0$ - through the use of the interest rate $i$, but inflation is also affected by the economy's inflation expectation $\pi^{e}$. With the simplifying assumptions that there is no other variable affecting (e.g., output or exchange rate) and that $\pi \in[0, \infty)$, we have the following marginal effects $\pi_{i}<0$ and $\pi_{\pi^{e}}>0$ for all $\left(i, \pi^{e}\right) \in R^{2}$. The actual economy`s inflation expectation is not observed by the central bank, such that it only knows its probability distribution. One can justify this assumption by assuming that the monetary authority has a department of forecasting, but its forecast is not precise, maybe due to some informational disadvantage compared to private forecasters. Suppose that $\pi^{\mathrm{e}} \sim \mathcal{N}\left(\mu, \sigma^{2}\right) \$$ like in our baseline model.

The central bank does not choose the interest rate based only on its own information, rather it also uses the inflation expectation $x$ reported by a forecaster, who may be a commercial bank or other kind of financial institution 9 . Once again, we assume that the agent who receives the information does not know anything about the sender. As in most of the cases the monetary authority gathers information from a pool of many forecasters, such that it may be hard to know even the distribution of the types of each one. Thus, the central bank uses the reported value $x$ to build its expected value of $\pi^{e}$, namely $\mathrm{E}\left(\pi^{\mathrm{e}}\right)=\mathrm{xP}(\mathrm{x})$, where $\mathrm{P}(\mathrm{x})$ is given by (2.1). By optimizing its payoff function $v(\mathrm{i}, \mathrm{x})$, we are able to obtain its best response

9 For the sake of simplicity, we assume one single sender in this application, even though in practice the central bank receives information from a large number of heterogeneous forecasters. A broader analyzes including many different forecasters would require a more complex macro framework. 
$\mathrm{i}\left(\mathrm{E}\left(\pi^{\mathrm{e}}\right)\right)$, with $\mathrm{i}^{\prime}(\cdot)>0$ for allx. This function can be seen as a simple Taylor rule and it is consistent with several straightforward functional forms of $\mathrm{v}(\mathrm{i}, \mathrm{x})^{10}$.

For the sake of simplicity, let the forecaster's utility be given by $\mathrm{u}(\mathrm{x}, \mathrm{i})=\mathrm{Ai}$, where the constant $\mathrm{A}>0$ means that he owns assets indexed to the economy's interest rate. Therefore, he wants to report the highest possible value in order to make the central bank increase $i$, which in turn increases his earnings as well. In a more general models, the utility's forecaster may also be affected by the inflation itself and other economic variables that depend on his report. The forecaster may be an investor whose assets are indexed to inflation, but his debts are indexed to $i$, for example. Notice that this situation would create ambiguous incentives to lie, once a high $x$ would increase both variables. By assuming the same assumptions of our baseline model, the forecaster is able to anticipate the central bank's best response $\mathrm{i}(\mathrm{xP}(\mathrm{x}))$, such that he will optimize $\mathrm{u}(\mathrm{x}, \mathrm{i})=\mathrm{Ai}(\mathrm{xP}(\mathrm{x}))$. The $\mathrm{FOC}$ of his problem is $\mathrm{Ai}^{\prime}(\mathrm{xP}(\mathrm{x}))(\mathrm{P}(\mathrm{x})+\mathrm{xP}(\mathrm{x}))=0$, which has the same solution as (2).

The conclusion of this straightforward application can be drawn from the proposition 2.5: the inflation expectation reported by the forecaster will be higher than the mean and thus the central bank will choose a level of interest rate higher than the one associated to this mean. Observe that in this one-shot communication game the actual inflation expectation plays no role in the forecaster's choice, which means that he will always lie unless $\pi^{e}=\mathrm{x}^{*}$. However, the forecaster will not always report a value higher than the $\pi^{e}$ : if the actual inflation expectation is high enough, then he will be better off by reporting a lower value, closer to the mean, given that the central bank knows only the distribution of $\pi^{e}$. This strong result depends on the set of simplifying assumption we have made, but it is particularly dependent on the fact that there is no penalty on his utility imposed by the central banker in case of reporting a lie. In practice - or in a dynamic model, like the one developed in section 2.3 - the central bank can observe $\pi^{e}$ with delay and then impose an expost punishment on the forecaster, which creates incentives not to lie. Under these circumstances, reputational issues become important and must be studied.

\section{Concluding Remarks}

We conclude by commenting some of the limitations imposed by the functional forms we adopted throughout the text. The results presented so far are based on the assumption that the actual fish size is normally distributed. In fact, we have used the symmetry around the mean, the bell-shaped form and other properties of the normal distribution to prove propositions 2.3 and 2.5, which in turn are used

10 For instance, with $\pi^{*}=0$, a linear payoff function such as $\mathrm{v}(\mathrm{i}, \mathrm{x})=\pi\left(\mathrm{i}, \pi^{\mathrm{e}}\right)=\alpha \mathrm{E}\left(\pi^{\mathrm{e}}\right)-\beta \mathrm{i}$ achieves zero inflation when $\mathrm{i}\left(\mathrm{E}\left(\pi^{e}\right)\right)=(\alpha \vee \beta) \mathrm{E}\left(\pi^{e}\right)$ and satisfies all the desirable properties above listed. 
to prove the subsequent results. Yet, any distribution $f$ whose shape is similar to the one of the normal - symmetric around the mean, $\mathrm{f}^{\prime}(\mathrm{x})>0$ if $\mathrm{x}<\mu$ and $\mathrm{f}^{\prime}(\mathrm{x})<0$ if $x>\mu$, and bell-shaped - would present similar results. We choose the normal due to its widely usage and simplicity. The extension of our model to different distributions is not straightforward, as one can see in the proof of the aforementioned propositions. In fact, it is not clear whether our results hold with distributions that do not have the same features as the normal.

The functional form of the probability assigned by his friends to the fisherman's report - equation (1) - is also ad hoc. One can wonder how dependent on this assumption our results are. A situation in which such a question may arise is when the fisherman's friends know that he has a utility that is increasing in the expected value of the fish size. Therefore, although they still do not know his whole utility function, they do know that it is increasing and thus that the fisherman has incentives to overstate the reported fish size. In this case, whenever a value below the mean is reported, they assign a probability higher than if one above the mean were reported. For example, they may believe that his incentives to lie are very strong, such that they assign the following probability to the reported fish size

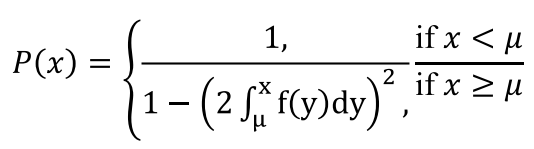

Several other functional forms are possible to model $\mathrm{P}(\mathrm{x})$, and the best choice depends on the information about the sender the receiver has. Once again, it is not clear whether our results hold with different functional forms, given that the properties of $\mathrm{P}(\cdot)$ are largely used in the proof of our main propositions.

Finally, the limitations our model also affect its applicability to the communication between a central bank and a forecaster. For instance, the ad hoc functional form chosen to represent the probability of the forecaster telling the truth - expression (1) - may not be a good description of the process central banks evaluate the reports' trustworthiness. It is also possible that the true inflation expectation is not normally distributed, as we have assumed. In fact, as we have seen, our results are quite sensitive to the choice of the probability distribution. The fact that we do not address the issue of multiple forecasters, and the potential strategic interaction among them, is another limitation of our approach that can be directly extended to the particular application we discuss in previous section. 


\section{References}

AMBRUS, A; TAKAHASHI, S. Multi-sender cheap talk with restricted state spaces. Theoretical Economics, v. 3, n.1, p. 1-27, Mar. 2008. Disponível em: https://econtheory.org/ojs/index.php/ te/article/view/20080001. Acesso em: 10 jan. 2018.

BATTAGLINI, M. Multiple referrals and multidimensional cheap talk. Econometrica, v.70, n. 4, p. 1379-1401, 2002. Disponível em: https://econpapers.repec.org/article/ecmemetrp/ v_3a70_3ay_3a2002_3ai_3a4_3ap_3a1379-1401.htm. Acesso em: 10 jan. 2018.

CABRAL, L M B. The economics of trust and reputation: a primer. New York University and CEPR, p. 1-30, Jun. 2005. Disponivel em: http://pages.stern.nyu.edu/ lcabral/reputation/ Reputation_June05.pdf. Acesso em: 10 jan. 2018.

CHAKRAVARTY, S; MA, Y; MAXIMIANO, S. Lying and friendship, n. 1008, Mar. 2011. Disponível em: https://ideas.repec.org/p/csr/wpaper/1008.html. Acesso em: 18 fev. 2018.

CRAWFORD, V P.; SOBEL, J. Strategic information transmission. Econometrica: Journal of the Econometric Society, v. 50, p. 1431-1451, Nov. 1982. Disponível em: https://www.econometricsociety.org/publications/econometrica/1982/11/01/strategic-information-transmission . Acesso em: 18 fev. 2018.

EPSTEIN, L G. An axiomatic model of non-Bayesian updating. The Review of Economic Studies, v. 73, n. 2, p.413-436, Apr. 2006. Disponível em: https://www.jstor.org/stable/3700645 . Acesso em: 18 fev. 2018.

EPSTEIN, L G.; NOOR, J; SANDRONI, A. Non-Bayesian updating: a theoretical framework. Theoretical Economics, v.3, n.2, p. 193-229, 2008. Disponível em: https://econtheory.org/ojs/ index.php/te/article/viewArticle/20080193. Acesso em: 18 fev. 2018.

EPSTEIN, L G.; NOOR, J.; SANDRONI, A. Non-bayesian learning. The BE Journal of Theoretical Economics, v. 10, n. 1, p. 1-20, 2010. Disponível em: https://www.degruyter.com/document/doi/10.2202/1935-1704.1623/html . Acesso em: 01 mar. 2018.

ERAT, S; GNEEZY, U. White lies. Management Science, v. 58, n. 4, p. 723733, 2012. Disponível em: https://econpapers.repec.org/article/inmormnsc/ v_3a58_3ay_3a2012_3ai_3a4_3ap_3a723-733.htm. Acesso em: 01 mar. 2018.

GILLIGAN, T. W.; KREHBIEL, K. Asymmetric information and legislative rules with a heterogeneous committee. American journal of political science, v. 33, n. 2, p. 459-490, May 1989. Disponível em: https://www.jstor.org/stable/2111156 . Acesso em: 01 mar. 2018.

GNEEZY, U. Deception: the role of consequences. American Economic Review, v. 95, n. 1, p. 384-394, Mar. 2005. Disponível em: https:/www.aeaweb.org/articles? id=10.1257/0002828053828662. Acesso em: 01 mar. 2018.

GREEN, J R.; STOKEY, N L. A two-person game of information transmission. Journal of economic theory, v. 135, n. 1, p. 90-104, 2007. Disponível em: https:/home.uchicago. edu/ nstokey/papers/Green\%208\%20Stokey\%20JET\%202007 . Acesso em: 05 mar. 2020. 
GRIEBLER, M. Strategically reported inflation expectation: a cheap-talk approach. Economics Bulletin, v. 39, n. 1, p. 264-269, 2019. Disponível em: https://ideas.repec.org/a/ebl/ecbull/ eb-18-00928.html . Acesso em: 05 mar. 2020.

KARTIK, N. Strategic communication with lying costs. The Review of Economic Studies, v. 76, n. 4, p. 1359-1395, Oct. 2009. Disponível em: https://academic.oup.com/restud/articleabstract/76/4/1359/1592392. Acesso em: 05 mar. 2018.

KRISHNA, V.; MORGAN, J. A model of expertise. The Quarterly Journal of Economics, v.116, n. 2, p. 747-775, May 2001. Disponível em: https://www.jstor.org/stable/2696478 . Acesso em: 05 mar. 2018.

LÓPEZ-PÉREZ, R.; SPIEGELMAN, E. Why do people tell the truth? Experimental evidence for pure lie aversion. Experimental Economics, v. 16, n. 3, p. 233-247, Sept. 2012. Disponível em: https://www.researchgate.net/publication/257561821_Why_Do_People_Tell_the_Truth_ Experimental_Evidence_for_Pure_Lie_Aversion. Acesso em: 07 mar. 2018.

MORRIS, S. Political correctness. Journal of political Economy, v. 109, n. 2, p. 231-265, Apr. 2001. Disponível em: https:/www.jstor.org/stable/10.1086/319554 . Acesso em: 07 mar. 2018.

SOBEL, J. Giving and receiving advice. Advances in economics and econometrics, v. 1, p. 305-341, May 2013. Disponível em: https:/www.cambridge.org/core/books/abs/advancesin-economics-and-econometrics/giving-and-receiving-advice/58CDB8E4F71CF96D948279 F2C9AF8D23. Acesso em: 07 mar. 2018.

STEIN, J. C. Cheap talk and the Fed: a theory of imprecise policy announcements. The American Economic Review, v. 79, n. 1, p. 32-42, Mar. 1989. Disponível em: https://www.jstor.org/ stable/1804771 . Acesso em: 07 mar. 2018.

\section{Appendix A - Omitted Proofs}

\section{A.1 Proposition 2.3}

Let us start by showing that $\mathrm{P}(\mathrm{x})$ is quasiconcave. Take any $\mathrm{K} \in(0,1)$ such that $\mathrm{P}(\mathrm{x})=\mathrm{K}$, then

$$
\mathrm{K}=1-\left(2 \int_{\mu}^{x} f(y) d y\right)^{2} \Rightarrow \int_{\mu}^{x} f(y) d y= \pm \frac{\sqrt{1-K}}{2}
$$


has two roots $\underline{x}<\mu$ and $\overline{\mathrm{x}}>\mu$, because $\mathrm{f}(\cdot)$ is the normal probability density function. In fact, $|\underline{x}-\mu|=|\bar{x}-\mu|$ due to the symmetry of $f(\cdot)$.

We must show that $P(x)>K$ for all $x \in(\underline{x}, \bar{x})$, which is equivalent to prove that an increase in makes the interval $(\underline{\mathrm{x}}, \overline{\mathrm{x}})$ smaller. In order to prove this statement, we write (9) as $g(K, x)=1-K-\left(2 \int_{\mu}^{x} f(y) d y\right)^{2}=0$ and then calculate the following derivative $d x / d K=-1 /\left(8 \int_{\mu}^{x} f(y) d y f(x)\right)$ through the implicit function theorem. Thus $\mathrm{dx} / \mathrm{dK}(\underline{\mathrm{x}})>0$, and $\mathrm{dx} / \mathrm{dK}(\overline{\mathrm{x}})<0$.

In order to see that $x=\mu$ is a unique global maximum of $P(x)$, observe that $P^{\prime}(x)=-8 \int_{\mu}^{x} f(y) \operatorname{dyf}(x)=0$ if and only if $x=\mu$, because $f(x)>0$ for all $x \in R$. As $P(x)$ is a quasiconcave function in the real line, then is a unique global maximum.

Finally, given that $\mathrm{P}(\mathrm{x})$ is quasiconcave, $\mathrm{x}=\mu$ is its unique global maximum, and $\mathrm{P}(\mathrm{x})>0$ for all $\mathrm{x} \in \mathrm{R}$, it is enough to observe that $\lim _{\mathrm{x} \rightarrow-\infty} P(x)=\lim _{\mathrm{x} \rightarrow+\infty} P(x)=0$ to prove that $\mathrm{P}(\mathrm{x})$ is bell-shaped.

\section{A. 2 Proposition 2.4}

Notice that we can write $\mathrm{U}(\mathrm{x})=\mathrm{u}(\mathrm{P}(\mathrm{x}))=\mathrm{xP}(\mathrm{x})$, where $\mathrm{u}(\mathrm{z})=\mathrm{xz}$ with $\mathrm{u}^{\prime}(\mathrm{z})=\mathrm{x}>0$ for all $\mathrm{x}>0$. Therefore, $\mathrm{U}(\mathrm{x})$ is a monotone transformation of $\mathrm{P}(\mathrm{x})$, which in turn is a quasiconcave function of . Thus $\mathrm{U}(\mathrm{x})$ is a quasiconcave function of for all $\mathrm{x}>0$ as well.

\section{A.3 Proposition 2.5}

Let us write $\mathrm{x}=\mu+\mathrm{n} \sigma$, with $\mathrm{n} \neq 0$ and given, substitute it into (2) and define

$$
G(\mu)=\left[1-\left(2 \int_{\mu}^{\mu+n \sigma} f(y) d y\right)^{2}\right]-8(\mu+n \sigma) f(\mu+n \sigma) \int_{\mu}^{\mu+n \sigma} f(y) d y
$$

We must show that $\mathrm{G}(\cdot)$ has a root $\bar{\mu}$ and thus, for given $\mathrm{n} \neq 0$ and , the FOC of the fisherman's problem has a root as well.

Given that $\mathrm{f}(\cdot)$ is the normal probability density function, we can observe that $\mathrm{f}(\mu+\mathrm{n} \sigma)$ and $\int_{\mu}^{\mu+\mathrm{no}} \mathrm{f}(\mathrm{y}) \mathrm{dy}$ do not depend on $\mu$. Therefore, for given values of $\mathrm{n} \neq 0$ and $\sigma$, the first term of the above expression is constant, non-negative and less than one - in fact, it is equal to $\mathrm{P}(\mathrm{x})$. One can also notice that $\mathrm{G}(\mu)$ is continuous, because $\mathrm{f}(\cdot)$ is continuous as well. Finally, it is straightforward to see that $\mathrm{G}^{\wedge}(\mu)<0$ for all $\mu \in \mathrm{R}$ and $\lim _{\mu \rightarrow-\infty} G(\mu)=+\infty$ and $\lim _{\mu \rightarrow+\infty} G(\mu)=-\infty$. Thus the intermediate value theorem applies, which states that there exists $\bar{\mu} \in \mathrm{R}$ such that $\mathrm{G}(\bar{\mu})=0$. 
Let the optimal solution be defined by $x^{*}=\bar{\mu}+n$. For $n=0$, we can observe that

$$
\frac{d U}{d x}(\mu)=\left[1-\left(2 \int_{\mu}^{\mu} f(y) d y\right)^{2}\right]-8 \mu f(\mu) \int_{\mu}^{\mu} f(y) d y=1>0
$$

such that we must have $\mathrm{n}>0$ associated to the optimal solution, that is $\mathrm{x}^{*}>\bar{\mu}$. We can also see that

$$
\begin{gathered}
\frac{\mathrm{dU}}{\mathrm{dx}}(\mu+\sigma)=\left[1-\left(2 \int_{\mu}^{\mu+\sigma} \mathrm{f}(\mathrm{y}) \mathrm{dy}\right)^{2}\right]-8(\mu+\sigma) \mathrm{f}(\mu+\sigma) \int_{\mu}^{\mu+\sigma} \mathrm{f}(\mathrm{y}) \mathrm{dy} \\
=1-4 \cdot 0.341344746^{2}-8 \frac{(\mu+\sigma)}{\sqrt{2 \pi \sigma^{2}}} 0.341344746<0
\end{gathered}
$$

for all $(\mu, \sigma) \in R_{++}^{2}$, where we use $f(\mu+\sigma)=1 / \sqrt{2 \pi e \sigma^{2}}$ and $\mathrm{f}(\mu+\sigma) \int_{\mu}^{\mu+\sigma} \mathrm{f}(\mathrm{y}) \mathrm{dy}=0.341344746$, by the table values of the normal distribution. In fact, $\mathrm{dU} / \mathrm{dx}(\mu+\sigma)=0$ if and only if either $\mu>0$ and $\sigma<0$ or $\mu>0$ and $\sigma>0$, such that for $(\mu, \sigma) \in \mathrm{R}_{++}^{2}$ we must have $\mathrm{n}<1$, that is, $\mathrm{x}^{*}<\mu+\mu$. Finally, as $\mathrm{U}(\cdot)$ is a quasiconcave function in $R_{+}$, the critical point is a unique maximizer.

We still have to prove that $\bar{\mu}>0$. By the definition above (equation (10)),

$$
\bar{\mu}=H(n)=\frac{\left[1-\left(2 \int_{\bar{\mu}}^{\bar{\mu}+n \sigma} f(y) d y\right)^{2}\right]}{8 f(\bar{\mu}+n \sigma) \int_{\bar{\mu}}^{\bar{\mu}+n \sigma} f(y) d y}-n .
$$

We have already proved that $x^{*}=\bar{\mu}+n \sigma>\bar{\mu}$, such that $0<\mathrm{n}<1$. Now observe that $H(n)$ is continuous, $\lim _{n \rightarrow 0} H(n)=+\infty$ and $\lim _{n} H(n)=0$, which implies that there exists $\bar{n}>0$ such that $\stackrel{n \rightarrow 0}{w}$ henever $n<\bar{n}$ we have $\bar{\mu}=H(n)>0$.

\section{A.4 Proposition 2.6}

We must show that

$$
\frac{\partial \mathrm{x}^{*}}{\partial \sigma^{2}}=-\frac{1}{\mathrm{U}^{\prime \prime}\left(\mathrm{x}^{*}\right)} \frac{\partial \mathrm{U}^{\prime}}{\partial \sigma^{2}}\left(\mathrm{x}^{*}\right)>0
$$


where we apply the implicit function theorem. Given that $\mathrm{U}^{\prime \prime}\left(\mathrm{x}^{*}\right)<0$ by proposition 2.5, the sign of the above expression is the same as the one of $\partial \mathrm{U}^{\prime}\left(\mathrm{x}^{*}\right) / \partial \sigma 2$. Thus, observe that

$$
\frac{\partial U^{\prime}}{\partial \sigma^{2}}\left(x^{*}\right)=-8 \int_{\mu}^{x^{*}} f(y) d y \int_{\mu}^{x^{*}} \frac{\partial f}{\partial \sigma^{2}}(y) d y-8 x^{*}\left[\frac{\partial f}{\partial \sigma^{2}}\left(x^{*}\right) \int_{\mu}^{x^{*}} f(y) d y+f\left(x^{*}\right) \int_{\mu}^{x^{*}} \frac{\partial f}{\partial \sigma^{2}}(y) d y\right]
$$

Because $f(\cdot)$ is a probability density function, $f\left(x^{*}\right)>0$ and $\int_{\mu}^{x^{*}} f(y) d y>0$. In addition, proposition 2.5 shows that, which implies that $\mathrm{x}^{*}<\mu+\mu$ and $\int_{\mu}^{\mathrm{x}^{*}} \partial \mathrm{f}\left(\mathrm{x}^{*}\right) / \partial \sigma^{2}<0$.
This in turn implies that $\partial \mathrm{f}\left(\mathrm{x}^{*}\right) / \partial \sigma^{2}<0$ and thus $\partial \mathrm{x}^{*} / \partial \sigma^{2}>0$.

\section{A.5 Proposition 2.7}

Let us start by proving statements 2 and 3 . In order to do so, assume that 1 is true, that is, the optimal solution $x^{*}(\tilde{x})$ exists. Let $x^{*}$ be the solution of the fisherman's problem without moral cost - the solution of the (2). Furthermore, recall that $x^{*}>\mu$. Observe that with the inclusion of the moral cost $\lambda(\cdot)$, the fisherman's problem has the following FOC:

$$
P(x)+x P^{\prime}(x)-2 \alpha(x-\tilde{x})=0
$$

We must then consider three cases.

First, suppose that $\tilde{\mathrm{x}}>\mathrm{x}^{*}>\mu$ and observe that

$$
\begin{gathered}
\mathrm{V}^{\prime}\left(\mathrm{x}^{*}\right)=-2 \alpha\left(\mathrm{x}^{*}-\tilde{\mathrm{x}}\right)>0 \\
\mathrm{~V}^{\prime}(\tilde{\mathrm{x}})=\mathrm{P}(\tilde{\mathrm{x}})+\tilde{\mathrm{x}} \mathrm{P}^{\prime}(\tilde{\mathrm{x}})
\end{gathered}
$$

implies $\mathrm{x}^{*}(\tilde{\mathrm{x}})>\mathrm{x}^{*}$ and $\mathrm{x}^{*}(\tilde{\mathrm{x}})<\tilde{\mathrm{x}}$. Therefore, we have $\mathrm{x}^{*}(\tilde{\mathrm{x}}) \in\left(\mathrm{x}^{*}, \tilde{\mathrm{x}}\right)$. The second case is $x^{*}>\mu>\tilde{x}$. Now, we have 


$$
\begin{aligned}
& V^{\prime}\left(\mathrm{x}^{*}\right)=-2 \alpha\left(\mathrm{x}^{*}-\tilde{\mathrm{x}}\right)<0 \\
& \mathrm{~V}^{\prime}(\tilde{\mathrm{x}})=\mathrm{P}(\tilde{\mathrm{x}})+\tilde{\mathrm{x}} \mathrm{P}^{\prime}(\tilde{\mathrm{x}})>0
\end{aligned}
$$

which implies $\mathrm{x}^{*}(\tilde{\mathrm{x}})<\mathrm{x}^{*}$ and $\mathrm{x}^{*}(\tilde{\mathrm{x}})>\tilde{\mathrm{x}}$.

Moreover,

$$
V^{\prime}(\mu)=1-2 \alpha(\mu-\tilde{x})>0
$$

if and only if $\tilde{x}+\frac{1}{2 \alpha}>\mu$. Therefore, in this case $x^{*}(\tilde{x}) \in\left(\mu, x^{*}\right)$ if $\tilde{x}+\frac{1}{2 \alpha}>\mu$ and $\mathrm{x}^{*}(\tilde{\mathrm{x}}) \in(\tilde{\mathrm{x}}, \mu]$ if $\tilde{\mathrm{x}}+\frac{1}{2 \alpha} \leq \mu$.

Finally, the third case is $x^{*}>\tilde{x}>\mu$. By evaluating (16) at $x^{*}$ and $\tilde{x}$ we have (19) and (20), respectively. Thus, $x(\tilde{x})^{*} \in\left(\tilde{x}, x^{*}\right)$. Therefore, one can observe that in any of the three cases the distance $\left|\mathbf{x}^{*}(\tilde{\mathrm{x}})-\tilde{\mathrm{x}}\right|$ is lower than . By the second case, we can also notice that as long as we have.

In order to prove 1 , notice that (3) can be rewritten as $U^{\prime}(x)-2 \alpha(x-\tilde{x})=0$. Once again, define $\mathrm{x}=\mu+\mathrm{n} \sigma$, with $\mathrm{n} \neq 0$ and $\sigma$ given, and write (3) as

$$
R(\mu)=G(\mu)-2 \alpha(\mu+n \sigma-\tilde{x})
$$

Given that $\mathrm{R}^{\prime}(\mu)=\mathrm{G}^{\prime}(\mu)-2 \alpha<0$ for all $\mu, \mathrm{R}(\mu)$ is continuous and $\lim _{\mu \rightarrow-\infty} R(\mu)=+\infty$ and $\lim _{\mu \rightarrow+\infty} H(\mu)=-\infty$, the intermediate value theorem applies,

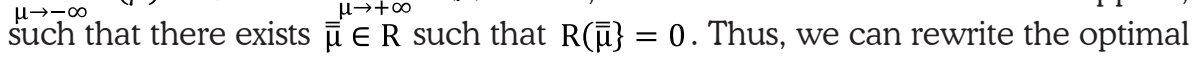
solution by $x^{*}(\tilde{x})=\overline{\bar{\mu}}+n$.

In order to show that is a maximum, notice that

$$
\mathrm{V}^{\prime \prime}\left(\mathrm{x}^{*}(\tilde{\mathrm{x}})\right)=2 \mathrm{P}^{\prime}\left(\mathrm{x}^{*}(\tilde{\mathrm{x}})\right)+\mathrm{x}^{*}(\tilde{\mathrm{x}}) \mathrm{P}^{\prime \prime}\left(\mathrm{x}^{*}(\tilde{\mathrm{x}})\right)-2 \alpha
$$

By the proof of the statements 2 and 3, we can see that $\lim _{\alpha \rightarrow \infty} x^{*}(\tilde{x})=\tilde{x}$. This implies that $\lim _{\alpha \rightarrow \infty} \mathrm{V}^{\prime \prime}\left(\mathrm{x}^{*}(\tilde{\mathrm{x}})\right)=-\infty$, so there exists $\bar{\alpha} \in \mathrm{R}$ such $\overrightarrow{\mathrm{th}}^{\infty}$ at if $\alpha>\bar{\alpha}$, then $\mathrm{V}^{\prime \prime}\left(\mathrm{x}^{*}(\tilde{\mathrm{x}})\right)<\stackrel{\alpha \rightarrow \infty}{0}$. In addition, $\lim _{\alpha \rightarrow 0} \mathrm{~V}^{\prime \prime}\left(\mathrm{x}^{*}(\tilde{\mathrm{x}})\right)=\mathrm{V}^{\prime \prime}\left(\mathrm{x}^{*}\right)<0$, so there exists $\underline{\alpha} \in \mathrm{R}$ such that if, we have $\left.\mathrm{V}^{\prime \prime}\left(\mathrm{x}^{*}(\tilde{\mathrm{x}})\right)\right)^{\alpha \rightarrow 0}<0$. 


\section{A.6 Proposition 2.8}

By proposition 2.5, we have: for given $\sigma^{2}$, there exists $\bar{\mu}$ such that (7) has solution $\mathrm{x}_{2}^{* *} ; \mathrm{x}_{2}^{* *}=\mathrm{x}_{1}^{*}>\bar{\mu}$, where $\mathrm{x}_{1}^{*}$ is the solution of the original static model; and $\mathrm{x}_{2}^{* *}$ is independent on $\widetilde{\mathrm{x}_{2}}$. We must then show that

$$
\mathrm{J}\left(\mathrm{x}_{1}\right)=\mathrm{x}_{1} \mathrm{P}^{\prime}\left(\mathrm{x}_{1}\right)+\mathrm{P}\left(\mathrm{x}_{1}\right)-2 \beta\left(\mathrm{x}_{1}-\widetilde{\mathrm{x}_{1}}\right) \mathrm{e}^{-\left(\mathrm{x}_{1}-\widetilde{\mathrm{x}_{1}}\right)^{2}} \mathrm{x}_{2}^{* *} \mathrm{P}\left(\mathrm{x}_{2}^{* *}\right)=0
$$

has roots. Observe that $\mathrm{J}\left(\mathrm{x}_{1}\right)$ is continuous, because it is composed by continuous functions. Let us consider the three cases analyzed in the proof of proposition 2.7 .

In the first case, suppose that $x_{2}^{* *}>\widetilde{x_{1}}>\bar{\mu}$. Then,

$$
\begin{gathered}
J\left(x_{2}^{* *}\right)=-C\left(x_{2}^{* *}-\widetilde{x_{1}}\right) e^{-\left(x_{2}^{* *-\widetilde{x_{1}}}\right)^{2}}<0 \\
J(\bar{\mu})=1-C\left(\bar{\mu}-\widetilde{x_{1}}\right) e^{-\left(\bar{\mu}-\widetilde{x_{1}}\right)^{2}}>0
\end{gathered}
$$

where $C=2 \beta x_{2}^{* *} P\left(x_{2}^{* *}\right)>0$ is a constant and we use the fact of $P(\bar{\mu})=1$. Thus, there exists $\mathrm{x}_{1}^{* *} \in\left(\bar{\mu}, \mathrm{x}_{2}^{* *}\right)$ such that $\mathrm{J}\left(\mathrm{x}_{1}^{* *}\right)=0$.

Second, suppose that $\widetilde{x_{1}}>x_{2}^{* *}>\bar{\mu}$. Then:

$$
\begin{gathered}
\mathrm{J}\left(\mathrm{x}_{2}^{* *}\right)=-\mathrm{C}\left(\mathrm{x}_{2}^{* *}-\widetilde{\mathrm{x}_{1}}\right) \mathrm{e}^{-\left(\mathrm{x}_{2}^{* *}-\widetilde{\mathrm{x}_{1}}\right)^{2}}>0 \\
\mathrm{~J}\left(\widetilde{\mathrm{x}_{1}}\right)=\widetilde{\mathrm{x}_{1}} \mathrm{P}^{\prime}\left(\widetilde{\mathrm{x}_{1}}\right)+\mathrm{P}\left(\widetilde{\mathrm{x}_{1}}\right)<0
\end{gathered}
$$

where the latter inequality follows from $\widetilde{x_{1}}>x_{2}^{* *}$ and proposition 2.5. Therefore, there exists $\mathrm{x}_{1}^{* *} \in\left(\mathrm{x}_{2}^{* *}, \widetilde{\mathrm{x}_{1}}\right)$ such that $\mathrm{J}\left(\mathrm{x}_{1}^{* *}\right)=0$.

Finally, consider the case in which $x_{2}^{* *}>\bar{\mu}>\widetilde{x_{1}}$. Now we have 


$$
\begin{gathered}
\mathrm{J}\left(\mathrm{x}_{2}^{* *}\right)=-\mathrm{C}\left(\mathrm{x}_{2}^{* *}-\widetilde{\mathrm{x}_{1}}\right) \mathrm{e}^{-\left(\mathrm{x}_{2}^{* *}-\widetilde{\mathrm{x}_{1}}\right)^{2}}<0 \\
\mathrm{~J}\left(\widetilde{\mathrm{x}_{1}}\right)=\widetilde{\mathrm{x}_{1}} \mathrm{P}^{\prime}\left(\widetilde{\mathrm{x}_{1}}\right)+\mathrm{P}\left(\widetilde{\mathrm{x}_{1}}\right)>0
\end{gathered}
$$

where we once again use the fact of $\widetilde{x_{1}}<x_{2}^{* *}$ and proposition 2.5. Thus, there exists $\mathrm{x}_{1}^{* *} \in\left(\widetilde{\mathrm{x}_{1}}, \mathrm{x}_{2}^{* *}\right)$ such that $\mathrm{J}\left(\mathrm{x}_{1}^{* *}\right)=0$. Notice also that $J(\bar{\mu})=1-C\left(\bar{\mu}-\widetilde{x_{1}}\right) e^{-\left(\bar{\mu}-\widetilde{x_{1}}\right)^{2}}$, such that $J(\bar{\mu})<0$ if and only if

$$
\beta>\frac{e^{\left(\bar{\mu}-\widetilde{x_{1}}\right)^{2}}}{2 x_{2}^{* *} P\left(x_{2}^{* *}\right)}=\bar{\beta}
$$

Thus, one can see that $\beta>\bar{\beta}$ implies $x_{1}^{* *} \in\left(\widetilde{x_{1}}, \bar{\mu}\right)$.

It is straightforward to see that all the ranges obtained above guarantee that $\left|\mathrm{x}_{2}^{* *}-\widetilde{\mathrm{x}_{1}}\right|>\left|\mathrm{x}_{1}^{* *}-\widetilde{\mathrm{x}_{1}}\right|$ for any set of parameters.

Now, observe that the second order derivatives of the fisherman's utility evaluated at the optimum $\left(\mathrm{x}_{1}^{* *}, \mathrm{x}_{2}^{* *}\right)$ are given by

$$
\begin{gathered}
\frac{\partial^{2} \mathrm{~W}}{\partial \mathrm{x}_{1}^{2}}\left(\mathrm{x}_{1}^{* *}, \mathrm{x}_{2}^{* *}\right)=2 \mathrm{P}^{\prime}\left(\mathrm{x}_{1}^{* *}\right)+\mathrm{x}_{1}^{* *} \mathrm{P}^{\prime \prime}\left(\mathrm{x}_{1}^{* *}\right)-2 \beta \mathrm{x}_{2}^{* *} \mathrm{P}\left(\mathrm{x}_{2}^{* *}\right) \mathrm{e}^{-\left(\mathrm{x}_{1}^{* *}-\widetilde{\mathrm{x}_{1}}\right)^{2}}\left[1-2\left(\mathrm{x}_{1}^{* *}-\widetilde{\mathrm{x}_{1}}\right)^{2}\right] \\
\frac{\partial^{2} \mathrm{~W}}{\partial \mathrm{x}_{1} \partial \mathrm{x}_{2}}\left(\mathrm{x}_{1}^{* *}, \mathrm{x}_{2}^{* *}\right)=-2\left(\mathrm{x}_{1}^{* *}-\widetilde{\mathrm{x}_{1}}\right) \mathrm{e}^{-\left(\mathrm{x}_{1}^{* *}-\widetilde{\mathrm{x}_{1}}\right)^{2}} \beta\left[\mathrm{P}\left(\mathrm{x}_{2}^{* *}\right)+\mathrm{x}_{1}^{* *} \mathrm{P}^{\prime \prime}\left(\mathrm{x}_{2}^{* *}\right)\right] \\
\frac{\partial^{2} \mathrm{~W}}{\partial \mathrm{x}_{2}^{2}}\left(\mathrm{x}_{1}^{* *}, \mathrm{x}_{2}^{* *}\right)=\beta \mathrm{e}^{-\left(\mathrm{x}_{1}^{* *}-\widetilde{\mathrm{x}_{1}}\right)^{2}}\left[\mathrm{x}_{2}^{* *} \mathrm{P}^{\prime \prime}\left(\mathrm{x}_{2}^{* *}\right)+2 \mathrm{P}^{\prime}\left(\mathrm{x}_{2}^{* *}\right)\right]
\end{gathered}
$$

Proposition 2.5 states that $\mathrm{P}\left(\mathrm{x}_{2}^{* *}\right)+\mathrm{x}_{1}^{* *} \mathrm{P}^{\prime \prime}\left(\mathrm{x}_{2}^{* *}\right)=0$ and $\mathrm{x}_{2}^{* *} \mathrm{P}^{\prime \prime}\left(\mathrm{x}_{2}^{* *}\right)+2 \mathrm{P}^{\prime}\left(\mathrm{x}_{2}^{* *}\right)<0$, so we have $\frac{\partial^{2} \mathrm{~W}}{\partial \mathrm{x}_{1} \partial \mathrm{x}_{2}}\left(\mathrm{x}_{1}^{* *}, \mathrm{x}_{2}^{* *}\right)=0$ and $\frac{\partial^{2} \mathrm{~W}}{\partial \mathrm{x}_{2}^{2}}\left(\mathrm{x}_{1}^{* *}, \mathrm{x}_{2}^{* *}\right)<0$. Hence, if we show that $\frac{\partial^{2} \mathrm{~W}}{\partial \mathrm{x}_{1}^{2}}\left(x_{1}^{* *}, \mathrm{x}_{2}^{* *}\right)<0$, the strict concavity of $W$ at $\left(\mathrm{x}_{1}^{* *}, \mathrm{x}_{2}^{* *}\right)$ is guaranteed. In order to do so, notice that $\lim _{\beta \rightarrow 0} x_{1}^{* *}=x_{1}^{*}$, such that $\lim _{\beta \rightarrow 0} \frac{\partial^{2} W}{\partial x_{1}^{2}}\left(x_{1}^{*}, x_{2}^{* *}\right)=2 \mathrm{P}^{\prime}\left(x_{1}^{*}\right)+x_{1}^{*} \mathrm{P}^{\prime \prime}\left(x_{1}^{*}\right)<0$ by proposition 2.5 . Thus, there exists $\bar{\beta} \in(0,1)$ such that if $\beta<\bar{\beta}$, we have $\frac{\partial^{2} \mathrm{~W}}{\partial \mathrm{x}_{1}^{2}}\left(\mathrm{x}_{1}^{* *}, \mathrm{x}_{2}^{* *}\right)<0$. 


\section{Contato do autor:}

Marcelo de Carvalho Griebeler

Recebido em: 24/07/2019.

E-mail: marcelo.griebeler@ufrgs.br

Aceito em: 06/02/2020.

\section{(cc) BY}

Este é um artigo de acesso aberto distribuído sob os termos da Creative Commons Attribution CC-BY 4.0, que permite uso irrestrito, distribuição e reprodução em qualquer meio, desde que o trabalho original seja devidamente citado. 